\section{Function and Viability of Ves- sels in Different Preservation Solutions - An Experimental Study on Human Great Saphe- nous Veins}

\author{
Verena Buchinger-Kähler ${ }^{1,2}$, Volker R Stoldt ${ }^{3}$, Thomas Muth ${ }^{4}$ \\ and Jochen D Schipke ${ }^{1 *}$
}

${ }^{1}$ Research Group Experimental Surgery, Department of Thoracic and Cardiovascular Surgery, University Hospital Düsseldorf, Düsseldorf, Germany

${ }^{2}$ Department of Plastic Surgery, Hand and Reconstructive Surgery, Burn Centre, University Hospital Aachen, Aachen, Germany

${ }^{3}$ Department of Hemostasis and Transfusion Medicine, Heinrich-Heine-University Medical Centre, Düsseldorf, Germany

${ }^{4}$ Institute of Occupational Medicine and Social Medicine, Heinrich-Heine-University, Düsseldorf, Germany

\section{Abstract}

\section{Objective}

Great Saphenous Veins (SVs) are widely used in coronary and in non-coronary surgery, and the need for vascular transplants is increasing. In older pre $\urcorner$ servation solutions, hypothermia leads to damage induced by reactive oxygen species. Iron chelators in the newer Tissue Protection (TiProtec) solution shall parnticularly protect vessels by preventing from that damage.

It was the aim to compare three preservation solutions to maintain function and viability of human SVs.

\section{Methods}

Vein segments were randomly assigned to Krebs-Henseleit Buffer (KHB), Viaspan (UW), or TiProtec. Contraction/relaxation in organ baths was assessed at $3,24,48$ and $72 \mathrm{~h}$ after removal. The protocol included three steps: receptor-independent contraction (KCl: $80 \mu \mathrm{M})$, receptor-dependent contraction (PE: $\leq 30 \mu \mathrm{M})$, endothelium-dependent relaxation (ACh: $\leq 20 \mu \mathrm{M})$. Morphology: Vein segments were incubated with propidium iodide and 5-chloromethylfluorescein diacetate. Viability was assessed with fluorescence using laser scanning microscopy.

*Corresponding author: Jochen D Schipke, Research Group Experimental Surgery, Department of Thoracic and Cardiovascular Surgery, University Hospital Düsseldorf, Düsseldorf, Germany, Tel: +49 2118114996; Fax: +492118115334; E-mail: j.schipke@gmx.org

Citation: Buchinger-Kähler V, Stoldt VR, Muth T, Schipke JD (2016) Function and Viability of Vessels in Different Preservation Solutions-An Experimental Study on Human Great Saphenous Veins. J Angiol Vasc Surg 1: 003

Received: October 29, 2015; Accepted: March 25, 2016; Published: April 08, 2016

\begin{abstract}
Results
KHB was inappropriate after only $3 \mathrm{~h}$. In TiProtec, SVs contraction/relaxation had increased further at $72 \mathrm{~h}$, but not in both other groups. More necrosis was found in KHB SVs than in UW or TiProtec at $3 \mathrm{~h}$. More viable cells were found in UW and in TiProtec SVs on day-1, while only few cells were viable in KHB on day-10.

Summary and conclusion

Even short storage of SVs in KHB is deleterious. UW preserved func $\neg$ tion better over time. The best functional and morphological results yielded TiProtec over time, and the amount of viable cells correlated with function. TiProtec seems a promising alternative for short- and mid-term hypothermic vein preservation.
\end{abstract}

Keywords: Hypothermia; Iron chelators; Preservation; Reactive oxygen species; Transplantation; Vessel

\section{Introduction}

In the last decades blood vessel transplantation and preservation have grown steadily in importance. Although storage of those vessels induces injury, mechanisms of injury due to cold storage have only recently been extensively studied. Injury due to cold storage and prevention from injury have already been exhibited for corneal cells, cultured endothelial cells, hepatocytes, rat mesenteric artery, segments of rat and pig aorta and lung epithelial cells [1-3]. The same is true for the human internal thoracic artery [4]. On the other hand, preservation solutions themselves can develop an inherent toxicity upon rewarming [5-7].

A number of studies have shown that hypothermia injury results from a growing pool of redox-active iron $[8,9]$. The iron mediates the formation of Reactive Oxygen Species (ROS) which in turn lead to lipid peroxidation, changes in mitochondria, and finally to cell death [10]. The rewarming when the tissue is transplanted exacerbates this process while iron chelators were shown to ameliorate the damage [1].

Presently used preservation solutions, developed in the early 1980 's, do not take cold-induced damage into account. These older solutions include Histidine-Tryptophan-Ketoglutarate (HTK) solution (Custodiol) and University of Wisconsin solution (Viaspan). HTK solution was the basis of the newer Tissue Protection (TiProtec) solution that was specially developed [4] for the preservation of blood vessels and therefore contains iron chelators.

Despite the growing need for vascular transplants, methods of preservation are not stringently established. The necessity for a preservation solution that is optimized for blood vessels becomes apparent from a recent retrospective study [11], which reports on a re-occlusion rate of 25\% 12-18 months after an aorto-coronary bypass operation. Causes of this problem are damage during preparation, unfavorable conditions of inflow or outflow in the region of the anastomosis, turbulences if vessel diameter is too small, and damage to the endothelium [12]. The protection of endothelial function is particularly important in preventing postoperative thrombosis and stenosis [13]. Some authors [14,15] view transplant failure as the long-term consequence of intima hyperplasia, which results from multifactorial damage to the endothelium. 
The great Saphenous Vein (SV) is a well-established preparation for autologous and allogenic vein grafts [16]. It serves as a bypass in cardiovascular procedures and for reconstruction or patch in vascular surgery. The SV is employed worldwide with more than $80 \%$ of all surgical heart procedures for myocardial revascularization performed with autologous vein grafts $[17,18]$. However, $25 \%$ of these vein conduits are already occluded after 1 year of surgery, and almost $75 \%$ are occluded 10 years after surgery [19]. It is easily conceivable that the results become even worse if SV need to be stored before allogenic usage. Thus, optimized preservation solutions for most appropriate storage are essential.

Both function and histology will be addressed in this study. Thus, some histological properties of the great saphenous vein are given: It has a thin intima covered by endothelium, which is separated from the media by a rudimentary internal elastic lamina. The media consists of a less prominent inner layer of longitudinal muscle fibres and a more prominent outer layer of circular muscle fibres. The adventitia is composed of connective tissue and contains the vasa vasorum [20].

The present study was designed to test the hypothesis that TiProtec preserves both function (i.e., smooth muscle contractility in an organ bath) and viability (as judged by confocal laser microscopy) of human SV better than the older Custodiol solution and the Viaspan solution.

\section{Material and Methods}

Veins were taken from patients at the University Clinic Düsseldorf who underwent an Aorto-Coronary Venous Bypass operation (ACVB). In the course of this operation a piece of the great Saphenous Vein (SV) was removed from the leg. Left-over pieces of vein were kept in physiological saline until the end of the operation, after which they could be used for the purposes of this study.

Patients gave their informed consent to the use of their left-over veins for experimental purposes. The Ethics Commission of the Medical Faculty of the Heinrich-Heine-University Düsseldorf had approved the study. Previous illnesses, medication, BMI, age and sex were recorded for each patient (Table 1). No exclusion criteria were specified in advance, except for clearly recognizable varicosis.

\begin{tabular}{|c|c|}
\hline Number of patients & 77 \\
\hline Sex $(\% ;$ females/males $)$ & $27 / 73$ \\
\hline Age [years; mean \pm SD] & $67.1 \pm 15.4$ \\
\hline BMI $\left[\mathrm{kg} \cdot \mathrm{m}^{-2}\right.$; mean \pm standard deviation] & $30.3 \pm 7.6$ \\
\hline
\end{tabular}

Table 1: Demographic data of the vessel donors.

In the laboratory of the Research Group Experimental Surgery the SV were carefully cut into segments at least $4 \mathrm{~mm}$ wide on a cooled rubber surface. Surrounding fatty tissue was removed. During these procedures veins were immersed in Krebs-Henseleit $(\mathrm{KH})$ buffer. A vein segment was discarded if it did not develop an initial tension of at least $3.0 \mathrm{mN}$ under $\mathrm{KCl}$. Vein segments were then stored at $4^{\circ} \mathrm{C}$ for up to $72 \mathrm{~h}$ in one of the preservation solutions under study.

\section{Preservation solutions}

The $\mathrm{KH}$ buffer was prepared fresh each day. It was titrated to $\mathrm{pH} 7.2$ at $37.0^{\circ} \mathrm{C}$ using $1 \mathrm{M}$ hydrochloric acid [21]. Carbogen (95\% $\mathrm{O}_{2} / 5 \% \mathrm{CO}_{2}$ ) bubbled through the solution raised $\mathrm{pH}$ to 7.4 (veins are very sensitive to variations in $\mathrm{pH}$ ).

The University of Wisconsin (UW) solution (Viaspan; Bristol-Myers Squibb GmbH \& Co. KGaA, München, DE) is comparatively viscous $\left(4.8 \mathrm{cP}\right.$ at $\left.4^{\circ} \mathrm{C}\right)$. Its $\mathrm{pH}$ at room temperature is 7.4 . The solution is clear, colorless to yellow, and stored under aseptic conditions, with $16 \mathrm{mg}$ dexamethasone, $40 \mathrm{IU}$ insulin and $200.000 \mathrm{IU}$ penicillin $\mathrm{G}$ added for organ preservation (information provided 2005 by the manufacturer Bristol-Myers Squibb Pharmaceuticals).

The TiProtec solution (Köhler Chemie GmbH, Bensheim, DE) (Table 2) was developed on the basis of the proven Histidine-Tryptophan-Ketoglutarate (HTK) solution (Köhler Chemie GmbH, Bensheim, DE). It contains two different iron chelators: deferoxamine $(0.1 \mathrm{mM}$ Desferal), which does not permeate the cell membrane, and LK614 $(20 \mu \mathrm{M})$, which does. In TiProtec histidine is replaced by acetylhistidine, which has a modified affinity to iron and is thus less toxic.

\begin{tabular}{|c|c|}
\hline Ingredient & Concentratio (mM) \\
\hline $\mathrm{Cl}^{-}$ & 103 \\
\hline$\alpha$-ketoglutarate & 2 \\
\hline aspartate & 5 \\
\hline $\mathrm{H}_{2} \mathrm{PO}_{4}^{-}$ & 1 \\
\hline $\mathrm{Na}^{+}$ & 16 \\
\hline $\mathrm{K}^{+}$ & 93 \\
\hline $\mathrm{Mg}^{2+}$ & 8 \\
\hline $\mathrm{Ca}^{2+}$ & 0.05 \\
\hline tryptophane & 2 \\
\hline saccharose & 30 \\
\hline $\mathrm{N}$-acetylhistidine & 30 \\
\hline glycine & 10 \\
\hline alanine & 5 \\
\hline glucose & 10 \\
\hline deferoxamine & 0.082 \\
\hline LK 614 & 0.017 \\
\hline $\mathrm{pH}\left(20^{\circ} \mathrm{C}\right)$ & 7.0 \\
\hline osmolarity (mosm/l) & 305 \\
\hline
\end{tabular}

\section{Function}

Veins were stored at $4^{\circ} \mathrm{C}$. They were randomly assigned to three groups and placed in organ baths (Föhr Medical Instruments $\mathrm{GmbH}$, Seeheim-Ober Beerbach, DE) for testing contraction and relaxation. The solution in the control group contained $\mathrm{KHB}(\mathrm{n}=26)$; experimental groups contained either UW solution $(n=26)$ or TiProtec $(n=25)$.

Function of the veins was studied at intervals of 3,24, 48 and $72 \mathrm{~h}$ after preservation began. After each interval, veins were carefully rinsed three times from inside and outside with KHB and warmed within $30 \mathrm{~min}$ to $37^{\circ} \mathrm{C}$. After the function tests, veins were placed in cooled opaque Eppendorf pipettes in fresh preservation solution and refrigerated at $4^{\circ} \mathrm{C}$ until the next test.

Initial tension of vein segments was adjusted to $12.5 \pm 0.4 \mathrm{mN}$; it took 20 to $40 \mathrm{~min}$ to achieve stable tension for $3 \mathrm{~min}$, after which testing began. If necessary, initial tension was reset between tests.

The following protocol was used in testing veins: 1) receptor independent contraction $(80 \mu \mathrm{M} \mathrm{KCl}), 2)$ receptor dependent contraction (cumulative in steps up to $30 \mu \mathrm{M}$ phenylephrine; Sigma-Aldrich Chemie GmbH, München, DE), 3) endothelium 
dependent relaxation (cumulative in steps up to $30 \mu \mathrm{M}$ acetylcholine; Sigma-Aldrich Chemie GmbH, München, DE).

\section{Morphology}

In the second part of the study, viability and necrosis of endothelial and smooth muscle cells were assessed over a period of 10 days.

Viable cells were visualized using CellTracker Green (5-chloromethylfluorescein diacetate; CMFDA; Invitrogen, Carlsbad, DE). Living cells containing CMFDA fluoresce in green. In order to visualize necrotic cells, vein segments were incubated with membrane impermeable propidium iodide (Sigma-Aldrich Chemie $\mathrm{GmbH}$, München, DE). After cell death propidium iodide can enter a cell and intercalate with DNA, leading to red fluorescence under an argon laser.

Fluorescence was tested at 1 and 10 days after removal using a laser scanning microscope (LSM510, Axiovert 100M; Zeiss, Jena, DE). Veins were cut at room temperature in a Petri dish to a size of $0.3 \times 0.5$ $\mathrm{cm}$. The quality of the stain was checked at $\times 10$ magnification. Then at $\times 40$ magnification the relation of viable to necrotic cells was assessed layer by layer in $7.5 \mu \mathrm{m}$ steps in order to differentiate endothelium (intima) from smooth muscle (media). Two veins were processed in this way for each of the three preservation solutions. An external observer blinded to the study protocol performed the observations.

\section{Statistics}

Raw data were protocolled using a computer and transferred to an Excel spread sheet. Three independent persons checked the data before they were transferred to the program used for statistical analysis (SPSS, Version 19; SPSS Inc, Chicago, US).

An Analysis of Variance (ANOVA) was performed after a check for normal distribution of data with the Kolmogorov-Smirnov test. The Greenhouse-Geisser correction for repeated measures was used; it leads to more conservative values, which were used in all subsequent analyses. In case of significant effects, a post-hoc Scheffé test was used for individual comparisons. Paired t-tests were used to compare initial and final values. Results with $\mathrm{p}<0.05$ were considered significant.

\section{Results}

A total of 91 patients that were scheduled for routine coronary artery bypass surgery donated vein grafts. Of these, 14 were discarded because they exhibited clearly recognizable signs of either surgical injury or varicose. Thus, 77 vein segments could be included into the study. Initial tests were conducted on the vein segments after $3 \mathrm{~h}$ storage in one of the preservation solutions. Already at this step there was a marked difference between the solutions. Only 15/26 (58\%) of the veins in $\mathrm{KH}$ buffer were suitable for further testing. In contrast, $18 / 26(69 \%)$ of those in UW solution and 19/25 (76\%) in TiProtec could be used for further tests.

\section{Receptor independent contraction using $\mathrm{KCl}$}

After $3 \mathrm{~h}$ (Figure 1) veins preserved in $\mathrm{KH}$ buffer were already slightly weaker $(20.1 \pm 3.5 \mathrm{mN}$; mean \pm standard deviation $)$ than those in the UW group $(29.1 \pm 7.3 \mathrm{mN})$ and significantly weaker than those preserved in TiProtec $(41.4 \pm 16.2 \mathrm{mN})$. After $72 \mathrm{~h}$ in KH buffer no contraction stronger than $12 \mathrm{mN}$ could be induced using $\mathrm{KCl}$. The standard deviation got smaller as preservation time increased, indicating that contractile vein function decreased uniformly in $\mathrm{KH}$ buffer.

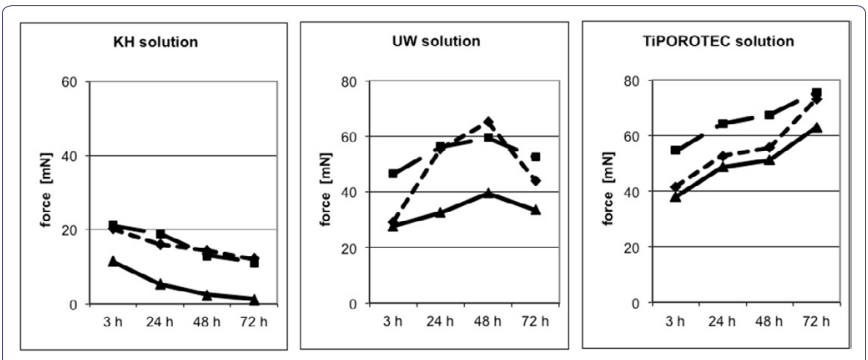

Figure 1: Contraction induced by Potassium Chloride $(\mathrm{KCl})$ and Phenylephrine $(P E)$ and relaxation by Acetylcholine (ACh). Human great saphenous vein rings were protected either in Krebs-Henseleit solution $(\mathrm{KH})$, or in University of Wisconsin solution (UW solution; Viaspan), or in TiProtec solution.

$\mathrm{KCl}$ : solid line; phenylephrine: dashed line; ACh: dash dotted line

For clarity, no standard deviation and significance symbols are presented. Please, see Results.

In the UW group function increased significantly up to $48 \mathrm{~h}$, reaching $65.0 \pm 31.0 \mathrm{mN}$, but it had decreased again after $72 \mathrm{~h}$ $(43.9 \pm 17.3 \mathrm{mN})$. After $24 \mathrm{~h}$ the UW solution was significantly better than $\mathrm{KH}$ buffer $(55.2 \pm 18.1$ vs. $16.0 \pm 5.8 \mathrm{mN})$.

In the TiProtec group contractile force increased steadily from $41.4 \pm 16.2 \mathrm{mN}$ after $3 \mathrm{~h}$, to $73.0 \pm 31.9 \mathrm{mN}$ after $72 \mathrm{~h}$, an overall increase of $76 \%$. After $72 \mathrm{~h}$ vein segments in the TiProtec contracted significantly stronger (Table 3 ) than either the segments of the $\mathrm{KH}$ group $(12.0 \pm 0.9 \mathrm{mN})$ or those of the $\mathrm{UW}$ group $(43.9 \pm 7.3 \mathrm{mN})$.

\begin{tabular}{|c|c|c|c|c|}
\hline & & $\begin{array}{c}\text { KH buffer } \\
n=9\end{array}$ & $\begin{array}{c}\text { UW solution } \\
n=11\end{array}$ & $\begin{array}{c}\text { TiProtec } \\
n=12\end{array}$ \\
\hline & & $\begin{array}{c}\text { mean } \pm S D \\
{[\mathrm{mN}]}\end{array}$ & $\begin{array}{c}\text { mean } \pm \text { SD } \\
{[\mathrm{mN}]}\end{array}$ & $\begin{array}{c}\text { mean } \pm S D \\
{[\mathrm{mN}]}\end{array}$ \\
\hline \multirow{4}{*}{ 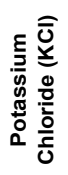 } & $3 \mathrm{~h}$ & $20.1 \pm 3.5^{+}$ & $29.1 \pm 7.3$ & $41.4 \pm 16.2$ \\
\hline & $24 \mathrm{~h}$ & $16.0 \pm 5.8^{* 0+}$ & $55.2 \pm 18.1^{*}$ & $52.6 \pm 29.3$ \\
\hline & $48 h$ & $14.3 \pm 2.8^{\star 0+}$ & $65.0 \pm 31.0^{*}$ & $55.5 \pm 28.0$ \\
\hline & $72 \mathrm{~h}$ & $12.0 \pm 0.9^{* 0+}$ & $43.9 \pm 17.3^{+}$ & $73.0 \pm 31.9$ \\
\hline \multirow{4}{*}{ 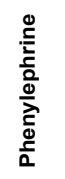 } & $3 \mathrm{~h}$ & $21.0 \pm 5.2^{\circ+}$ & $46.4 \pm 13.3$ & $54.6 \pm 17.8$ \\
\hline & $24 h$ & $18.7 \pm 7.1^{\circ+}$ & $56.2 \pm 16.7$ & $64.2 \pm 28.6$ \\
\hline & $48 h$ & $12.8 \pm 1.0^{* 0+}$ & $59.6 \pm 15.3$ & $67.4 \pm 29.7$ \\
\hline & $72 \mathrm{~h}$ & $11.0 \pm 2.3^{* 0+}$ & $52.4 \pm 20.6^{+}$ & $75.5 \pm 23.6$ \\
\hline \multirow{4}{*}{ 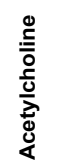 } & $3 \mathrm{~h}$ & $11.4 \pm 5.3^{\circ+}$ & $27.6 \pm 9.9$ & $38.1 \pm 15.1$ \\
\hline & $24 h$ & $5.2 \pm 4.6^{\star 0+}$ & $32.5 \pm 12.7^{*}$ & $48.7 \pm 30.5$ \\
\hline & $48 h$ & $2.2 \pm 1.0^{* 0+}$ & $39.5 \pm 16.5$ & $51.2 \pm 28.3$ \\
\hline & $72 \mathrm{~h}$ & $1.0 \pm 0.7$ & $33.4 \pm 16.7^{\circ+}$ & $63.0 \pm 21.8$ \\
\hline
\end{tabular}

Table 3: Contraction induced by $\mathrm{KCl}$ and $\mathrm{PE}$ and relaxation by $\mathrm{ACh}$.

Data are mean \pm Standard Deviation (SD)

${ }^{*} p<0.05$ vs preceding time point; ${ }^{\circ} p<0.05$ vs UW solution; ${ }^{+} p<0.05$ vs TiProtec

\section{Receptor dependent contraction using Phenylephrine (PE)}

Increasing the PE dosage cumulatively from $0.3 \mu \mathrm{M}$ to $30 \mu \mathrm{M}$ induced a maximal $\alpha$-receptor contraction of the segment. The results in this part of the experiment were comparable to those on receptor independent contraction. After $3 \mathrm{~h}$ the contraction force of vein segments was significantly lower in the KH buffer than in either of the other two groups: $21.0 \pm 5.2 \mathrm{mN}$ as compared to $46.4 \pm 13.1 \mathrm{mN}$ (UW) and $54.6 \pm 17.8 \mathrm{mN}$ (TiProtec). The differences remained significant at each of the later times (Table 3). As was the case using $\mathrm{KCl}$, contractile force in the TiProtec group increased steadily, while it 
Citation: Buchinger-Kähler V, Stoldt VR, Muth T, Schipke JD (2016) Function and Viability of Vessels in Different Preservation Solutions-An Experimental Study on Human Great Saphenous Veins. J Angiol Vasc Surg 1: 003.

slightly decreased in the UW group after $48 \mathrm{~h}$ (Table 3 ). After $72 \mathrm{~h}$ TiProtec was significantly superior: $75.5 \pm 23.6 \mathrm{mN}$ as compared to $11.0 \pm 2.3 \mathrm{mN}$ (KH buffer) and $52.4 \pm 20.6$ (UW solution).

\section{Endothelium dependent relaxation using Acetylcholine (ACh)}

The behavior of the vein segments during relaxation from maximal contraction $(30 \mu \mathrm{M} \mathrm{PE})$ was comparable to what was observed in the contraction series. The ability of veins in $\mathrm{KH}$ buffer to relax decreased steadily with time (Table 3 ) from $11.4 \mathrm{mN}(3 \mathrm{~h})$ to $1.0 \mathrm{mN}(72 \mathrm{~h})$. Relaxation was significantly better at all times in the other two groups. After $72 \mathrm{~h}$, relaxation of veins in the TiProtec group was better than in the UW group $(63.0 \pm 21.8 \mathrm{mN}$ as compared to $33.4 \pm 16.7 \mathrm{mN})$.

Morphology. After only $3 \mathrm{~h}$ the muscular layer in the $\mathrm{KH}$ buffer group appeared somewhat coarser and more loosely packed compared to the other two groups, and more necrotic cells were found, mostly of endothelial origin (Figure 2A). After 10 days there were almost no viable cells or coherent tissue to be seen (Figure 2B).
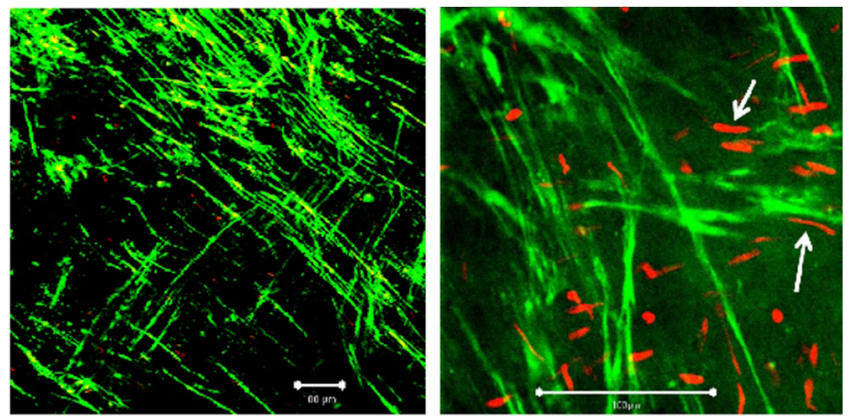

Figure 2A: Segment of vein from the $\mathrm{KH}$ group on day 1. Left: X10 magnification; white bar: $100 \mu \mathrm{m}$, right: detail (X40 magnification; white bar: $100 \mu \mathrm{m})$. White arrows: smooth muscle cell.
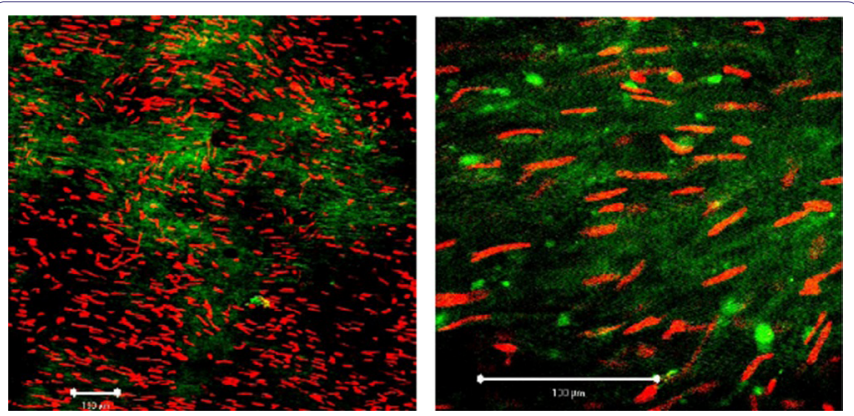

Figure 2B: Segment of vein from the $\mathrm{KH}$ group on day 10. Left: $\mathrm{X} 10$ magnification; white bar: $100 \mu \mathrm{m}$, right: detail (X40 magnification; white bar: $100 \mu \mathrm{m}$ ). Compared to first day (Figure 2a) red fluorescence (= necrotic cells) has clearly increased.

In the UW group myocytes also appeared to be more loosely packed and necrotic endothelial cells were found after 10 days cold storage (Figure 3), but not to the extent seen in the veins in $\mathrm{KH}$ buffer. The structure of the venous wall was partially loosened, but it was very much better preserved than in the veins of the $\mathrm{KH}$ group. Thus, stable contraction and relaxation behavior was still observed up to $48 \mathrm{~h}$. There was no difference between the UW and TiProtec groups on day 1 , with viable cells clearly forming a coherent tissue (Figure 4).

Even after 10 days in TiProtec no coarsened matrix was observed and the number of necrotic endothelial cells was noticeably fewer than in either of the other two groups (Figure 5).

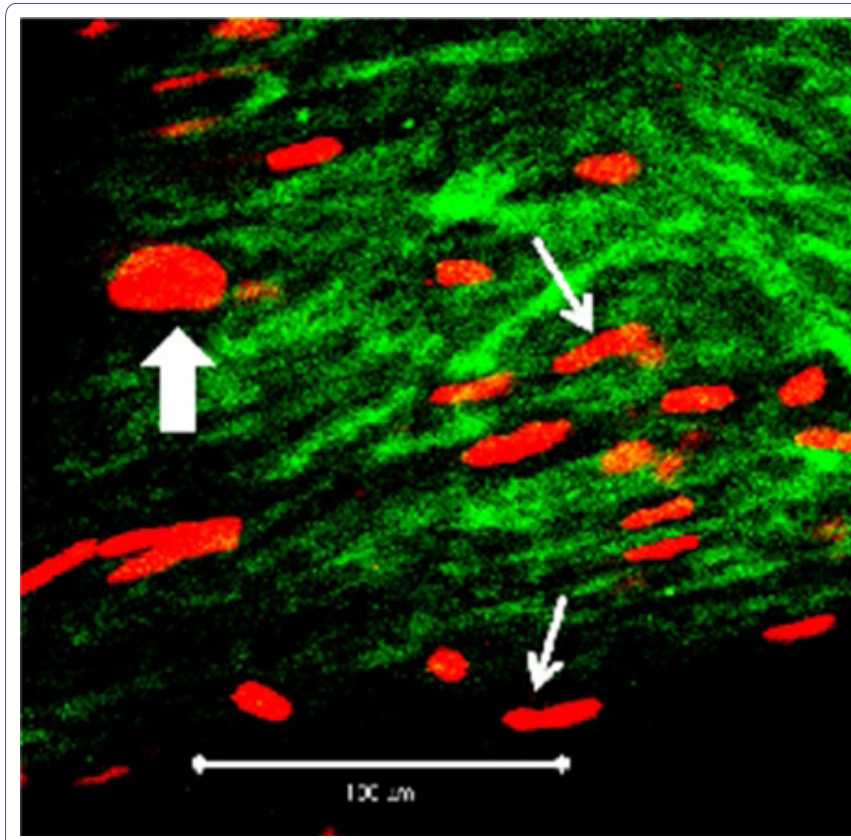

Figure 3: Segment of vein from the UW group on day 10 (detail at $X 40$ magnification; white bar: $100 \mu \mathrm{m}$ ). Viable cells fluoresce in green, apoptotic cells in red. Heavy arrow: PI-positive endothelial cell, thin arrows: PI-positive myocytes.

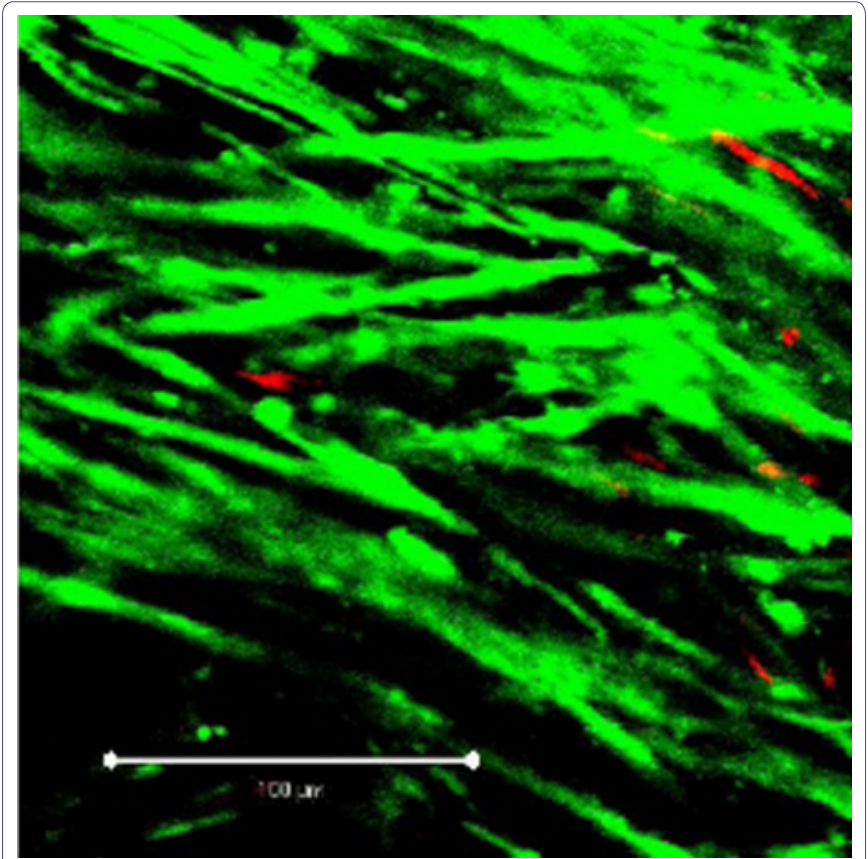

Figure 4: Segment of vein from the TiProtec group on day 1 (detail at X40 magnification; white bar: $100 \mu \mathrm{m})$.

\section{Discussion}

It is the main finding of this experimental study on human saphenous veins that the newer preservation solution (TiProtec), especially designed for use with blood vessel transplants, proved significantly superior to either $\mathrm{KH}$ buffer or $\mathrm{UW}$ solution in the $\mathrm{KCl}$ contraction test after only $3 \mathrm{~h}$ preservation. Thus, TiProtec appears well suited for short-term preservation (e.g., in bypass operations). On the other hand, $\mathrm{KH}$ buffer does not seem appropriate even for temporary storage in the operating theater. For 1 to 3 days storage, 


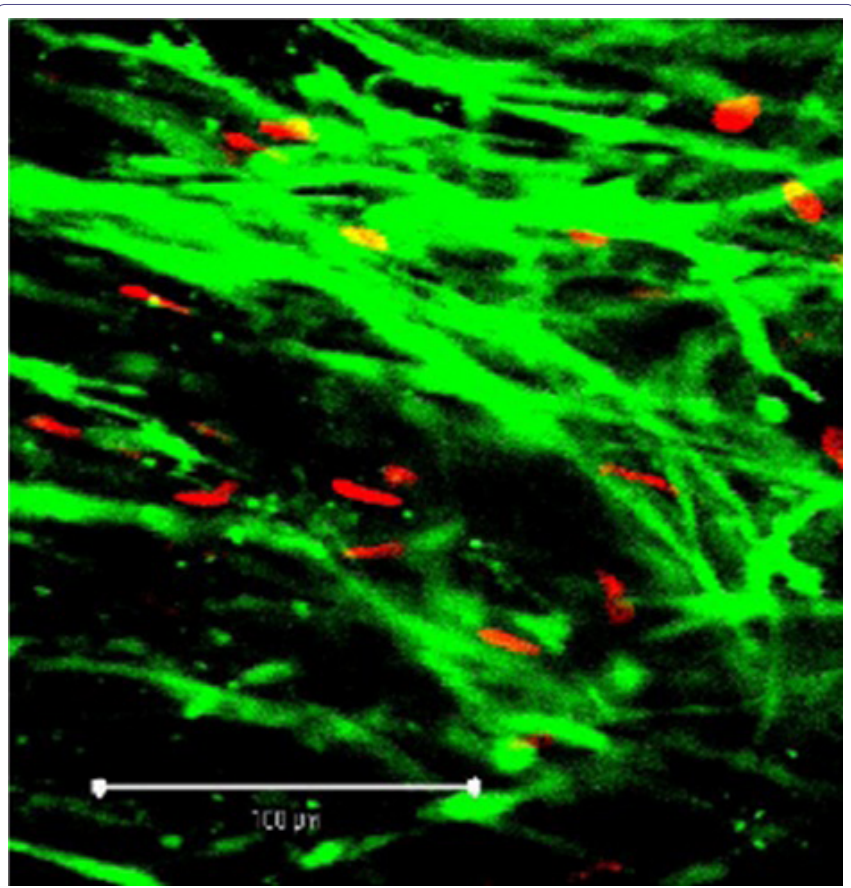

Figure 5: Segment of vein from the TiProtec group on day 10 (detail at $\mathrm{X} 40$ magnification; white bar: $100 \mu \mathrm{m}$ ). Only a few PI-positive cells can be seen. Unlike the other 2 solutions, this preservation solution maintains cellular structure (green)

both UW solution and TiProtec give comparably good results compared to $\mathrm{KH}$ buffer. From four days preservation or longer, TiProtec is clearly superior.

The present results also exhibit a relation between viable and necrotic cells on the one hand and contraction and relaxation of the veins stored in the three preservation solutions on the other hand. It thus appears that improved cell morphology is the reason for the improved contraction and relaxation behavior under TiProtec. One may expect that a well preserved transplant can minimize the risk of primary failure and later dysfunction after implantation.

\section{Study Limitations}

There are necessarily certain limits to applying the results of organ bath experiments to in vivo reality. Nevertheless, the results of earlier studies as well as those presented here clearly show that the results of animal experiments can be applied to human blood vessels.

Although Vasa Vasorum (VV) in saphenous grafts are needed for the nutrition of the vessel wall, the presence of the $\mathrm{VV}$ in our three groups was not assessed. However, the density and the distribution of VV had shown to be uniform and not to differ in great and small saphenous veins [22]. Thus, any damage on VV of our saphenous grafts would have affected the results within the three groups to a similar extent, i.e., differences in VV very unlikely can explain the observed differences described for the three different protection solutions.

Because of an average age of $67.1 \pm 15.4$ years, presence of varicose veins was to be expected and could have affected the results. For such veins, differences in the orientation of the Smooth Muscle Cells (SMC) in the inner and outer wall layers were reported, but the SMC orientation was uniform along the varicose saphenous veins [23] Thus, we do not consider changes in the SMC orientation responsible for the differences found for the protective solutions, in particular, because veins with clearly recognizable varicose had been discarded.
A final drawback of the study could have resulted from the conventional technique of harvesting the vein grafts in this study opposed to the no-touch technique that has been recommended by some groups, because it provided a significantly higher patency [24] and left ventricular ejection fraction [25] at a mean time of 16 years than the conventional technique.

Kopjar and Dashwood [26] focused on a critical aspect of the no-touch vein harvest that presents a major barrier to wide-spread adoption, which being the morbidity of the leg incision. Because all vein grafts in this study were harvested using the conventional technique, different solution-dependent results cannot be explained by different techniques.

Veins are rather small, and during storage they are bathed both inside and out by preservation solution, which means that both inner and outer surfaces are subject to the same oxygen partial pressure [27]. Damage due to hypoxia is thus less pronounced than for blood vessels within large organs. On the other hand normoxia promotes oxidation processes and the formation of free radicals.

Solutions for preserving blood vessels are now expected to maintain good function and morphology for about two weeks. This length of time is required in order to perform the microbiological tests prescribed by the European guidelines and the German tissue bank law [16].

In the present study the ability of a newer extracellular solution (TiProtec) to preserve human Saphenous Vein (SV) was examined for up to $72 \mathrm{~h}$ after removal. TiProtec was compared with the clinically established, intracellular University of Wisconsin (UW) solution. The controls were veins stored in Krebs-Henseleit $(\mathrm{KH})$ buffer. Two independent parts of the study were performed to evaluate preservation ability: in the functional part (organ bath) receptor independent and receptor contraction as well as endothelium dependent relaxation were measured. In the morphological part of the study (confocal laser microscopy) cell viability was investigated.

In the following some of the peculiarities of the preservation solutions used in this study are discussed. The functional and morphological results are viewed in connection with the current literature.

Krebs Henseleit $(\mathrm{KH})$ buffer is frequently employed in experiments using organ baths, cell culture or perfusion. Its $\mathrm{pH}$ value depends on continuous bubbling of $95 \% \mathrm{O}_{2} / 5 \% \mathrm{CO}_{2}$ through the solution. Without this precaution the $\mathrm{pH}$ becomes alkaline. The poor results found in this study with this solution might have been due to this factor, since alkaline $\mathrm{pH}$ causes serious damage to stored organs [27]. However, the time course of $\mathrm{pH}$ was not measured in this study.

The morphology, too, gives an indication of the importance of gassing the solution. Cultured hepatocytes have been preserved in $\mathrm{KH}$ buffer both with and without gassing [28]. Without gassing $4 \mathrm{~h}$ in cold storage induced considerable cell damage, as documented by the massive increase in the number of necrotic cells seen using Propidium Iodide (PI).

A further reason for the poor results with $\mathrm{KH}$ buffer might have to do with the high concentration of redox-active metals [29], which contribute to the development of Reactive Oxygen Species (ROS) during cold storage and subsequent rewarming. This damage mechanism is not observed with normothermic storage at $37^{\circ} \mathrm{C}$, such as is required for cell cultures. 
Even on day 1 of preservation veins showed slight morphological changes, such as loosened structure and a somewhat higher number of PI-positive cells. On day 10 there were almost no viable cells and necrotic cells dominated in all cell layers. Thus, $\mathrm{KH}$ buffer appears unsuitable for the cold storage of veins.

The University of Wisconsin (UW) solution is frequently used for the preservation of abdominal organs. The UW solution belongs to the intracellular solutions owing to its high $\mathrm{K}^{+}(125 \mathrm{mM})$ and low $\mathrm{Na}^{+}$concentration $(29 \mathrm{mM})$. Disadvantages of this solution include endothelial dysfunction [5] and in the case of lung transplants vasoconstriction and reduced compliance.

A major concern in the case of UW solution is the prevention of hypothermia induced cell swelling, which presumably results from inactivation of the $\mathrm{Na}^{+}-\mathrm{K}^{+}$-ATPase. The ensuing influx of $\mathrm{Na}^{+}$and $\mathrm{Cl}^{-}$ions draws water into the cells osmotically. To prevent this, UW solution contains lactobionic acid, raffinose and Hydroxyethyl Starch (HES). Lactobionic acid also acts as a chelator of $\mathrm{Ca}^{2+}$ and iron, which has been suggested to contribute to its effectiveness in preserving cell integrity during hypothermic storage. UW solution also contains glutathione, which as an antioxidant has a protective effect on liver transplants [30]. On the detrimental side, however, glutathione has been shown to cause increased endothelial dysfunction in cold storage [31].

The UW solution has proven useful for the preservation of liver, kidney and pancreas among other organs for 8 to $12 \mathrm{~h}$, sometimes as long as $24 \mathrm{~h}$. It is also used for heart transplants. The clinical importance of this solution is thus apparent.

The protective properties of the UW solution are temperature dependent. An inherent toxicity has been observed during the rewarming phase [5-7], which appears to be the result of a cold induced mechanism mediated by ROS [32]. This cold induced damage has been studied morphologically [32]. One hour after rewarming DNA fragmentation and apoptotic changes were observed, along with a 2.5-fold increase in PI uptake, a sign of more necrotic cells. Such damage was alleviated by adding an iron chelator [32].

In the present study, a stable contraction and relaxation behavior was observed up to $48 \mathrm{~h}$ after 10 days of cold storage, a result that was likely owing to the well maintained morphology.

The Tissue Protection (TiProtec) solution was specially developed on the basis of the Custodiol-N solution [33], which in turn was derived from the HTK solution (Custodiol) for liver preservation.

As hypoxic damage is of little importance in the case of thin-walled vessels, avoidance of other damage mechanisms was of primary concern in developing TiProtec. One concern was histidine, which serves as buffer in Custodiol but enhances iron formation at high concentrations [2]. For this reason, in TiProtec histidine was replaced by $\mathrm{N}$-acetylhistidine $(\mathrm{pK}=7.2$ ), which has a different affinity for redox-active iron and forms more stable complexes [2].

Another concern was the normoxia during hypothermic preservation, which can lead in particular to ROS induced endothelial damage. In order to avoid this source of damage at most, TiProtec contains two different iron chelators: desferoxamine, which is hydrophilic and does not pass through the cell membrane, and LK 614 [34], which being lipophilic easily passes through the membrane.

Comparatively little solution is required for preserving blood vessels. Hence, amino acids and ions can be used effectively to supply energy and regulate osmolarity. For example, replacing lactobionate anions with chloride led to a significantly increased rate of survival of endothelial cells in segments of pig aorta [3], a result that was confirmed using segments of rat aorta and mesenteric artery [35]. By using a high $\mathrm{K}+$ concentration $(93 \mathrm{mM})$, the mitochondrial membrane potential was better maintained [14] and vasoconstriction and EDHF-mediated relaxation were better than under the HTK solution, the extracellular-type solution used as a starting point [35].

A final concern in the design of TiProtec has to do with the amino acids glycine and alanine, which had already proven useful in the Custodiol-N solution for preventing $\mathrm{Na}^{+}$influx during hypoxia. These two amino acids were retained in the TiProtec solution for their membrane stabilizing properties, and aspartate and $\alpha$-ketoglutarate were added for maintaining the citric acid cycle [36].

Based on its advanced composition, TiProtec has led to excellent experimental results. Segment of pig aorta have been preserved for up to 21 days [3]. With segments of rat aorta and mesenteric artery, potassium induced vasoconstriction, both endothelium dependent and independent relaxation, eNOS expression and endothelial ultrastructure were all significantly better after four days preservation in TiProtec than in HTK solution [34]. Endothelial structure had already been lost after $2 \mathrm{~h}$ in HTK solution, a result that underscores the importance of employing the most appropriate preservation solution as early as possible.

Studies of human thoracic artery (ATI) [4] yield similarly positive results, as does the present study using human veins. For ATI, too, vascular tone was better preserved after four days in the TiProtec solution than in either $0.9 \% \mathrm{NaCl}$ or the HTK solution.

The damage caused by cold storage and rewarming has already been studied morphologically [3]. No matter which preservation solution was used, the number of PI-positive cells was reduced when iron chelators were added. Of the solutions tested, only TiProtec contains iron chelators as part of its formula. As shown in the present study, iron chelators appear able to effectively reduce damage due to ROS, in particular the number of necrotic endothelial cells was definitely lower than in the other two solutions, a finding that is in good agreement with a previous study on human SV segments [17]. The present study shows in addition that TiProtec also very adequately preserves contractile function.

The human great Saphenous Vein (SV) is clearly a representative model of a blood vessel transplant. SV may also be viewed as a simplified model of an organ containing numerous blood vessels, which must be preserved. This is especially true if an intact vascular endothelium is essential to the function of the organ. It should be remembered, however, that veins induce an immune reaction in the recipient, so they must be protected from being rejected after transplantation.

The clinical importance of the TiProtec solution has remained an open question. Currently available results indicate that TiProtec, specifically designed for use with blood vessels, is a good alternative for the short- and long-term preservation of vessels stored in hypothermia. Given the increasing numbers of blood vessel transplantations, not just clinical considerations but also economic aspects are gaining greater importance. Thus, a comprehensive cost-benefit analysis ought to include both the ease of use of TiProtec and the resulting lower rate of reocclusion and reoperation. 
Citation: Buchinger-Kähler V, Stoldt VR, Muth T, Schipke JD (2016) Function and Viability of Vessels in Different Preservation Solutions-An Experimental Study on Human Great Saphenous Veins. J Angiol Vasc Surg 1: 003.

\section{References}

1. Pizanis N, Gillner S, Kamler M, de Groot H, Jakob H, et al. (2011) Cold-induced injury to lung epithelial cells can be inhibited by iron chelators - implications for lung preservation. Eur J Cardiothorac Surg 40: 948-955.

2. Rauen U, Kerkweg U, Wusteman MC, de Groot H (2006) Cold-induced injury to porcine corneal endothelial cells and its mediation by chelatable iron: implications for corneal preservation. Cornea 25: 68-77.

3. Wille $\mathrm{T}$, de Groot $\mathrm{H}$, Rauen $\mathrm{U}$ (2008) Improvement of the cold storage of blood vessels with a vascular preservation solution. Study in porcine aortic segments. J Vasc Surg 47: 422-431.

4. Garbe S, Zatschler B, Müller B, Dieterich P, Ebner A, et al. (2011) Preservation of human artery function following prolonged cold storage with a new solution. J Vasc Surg 53: 1063-1070.

5. Mankad P, Slavik Z, Yacoub M (1992) Endothelial dysfunction caused by University of Wisconsin preservation solution in the rat heart. The importance of temperature. J Thorac Cardiovasc Surg 104: 1618-1624.

6. Amrani M, Ledingham S, Jayakumar J, Allen NJ, Rothery S, et al. (1992) Detrimental effects of temperature on the efficacy of the University of Wisconsin solution when used for cardioplegia at moderate hypothermia. Comparison with the St. Thomas Hospital solution at 4 degrees $\mathrm{C}$ and 20 degrees $\mathrm{C}$ Circulation 86: 280-288.

7. Ou R, Gavin JB, Esmore DS, Rosenfeldt FL (1999) Increased temperature reduces the protective effect of University of Wisconsin solution in the heart. Ann Thorac Surg 68: 1628-1634.

8. Rauen U, Polzar B, Stephan H, Mannherz HG, de Groot H (1999) Cold-induced apoptosis in cultured hepatocytes and liver endothelial cells: mediation by reactive oxygen species. FASEB J 13: 155-168.

9. Rauen U, de Groot H (2002) Mammalian cell injury induced by hypothermiathe emerging role for reactive oxygen species. Biol Chem 383: 477-488.

10. Rauen U, Petrat F, Li T, De Groot H (2000) Hypothermia injury/cold-induced apoptosis--evidence of an increase in chelatable iron causing oxidative injury in spite of low O2-/H2O2 formation. FASEB J 14: 1953-1964.

11. Lopes RD, Mehta RH, Hafley GE, Williams JB, Mack MJ, et al. (2012) Relationship between vein graft failure and subsequent clinical outcomes after coronary artery bypass surgery. Circulation 125: 749-756.

12. O'Neil GS, Chester AH, Schyns CJ, Tadjkarimi S, Borland JA, et al. (1994) Effect of surgical preparation and arterialization on vasomotion of human saphenous vein. J Thorac Cardiovasc Surg 107: 699-706

13. Neil DA, Lynch SV, Hardie IR, Effeney DJ (2002) Cold storage preservation and warm ischaemic injury to isolated arterial segments: endothelial cell injury. Am J Transplant 2: 400-409.

14. Towne JB (1989) Role of fibrointimal hyperplasia in vein graft failure. Journal of Vascular Surgery 10: 583-585.

15. Bailey LE, Ong SD (1978) Krebs-Henseleit solution as a physiological buffer in perfused and superfused preparations. J Pharmac Meth 2: 171-175.

16. Kolh P, Windecker S, Alfonso F, Jean-Philippe Collet, Cremer J, et al. (2014) 2014 ESC/EACTS Guidelines on myocardial revascularization The Task Force on Myocardial Revascularization of the European Society of Cardiology (ESC) and the European Association for Cardio-Thoracic Surgery (EACTS) Developed with the special contribution of the European Association of Percutaneous Cardiovascular Interventions (EAPCI). Eur J Cardiothorac Surg 46: 517-592.

17. Wilbring M, Tugtekin SM, Zatschler B, Ebner A, Reichenspurner $\mathrm{H}$, et al. (2013) Preservation of endothelial vascular function of saphenous vein grafts after long-time storage with a recently developed potassium-chloride and $\mathrm{N}$-acetylhistidine enriched storage solution. Thorac Cardiovasc Surg 61: 656662
18. Ferrari E, von Segesser L, Berdajs D (2015) Improving coronary artery bypass graft durability: use of the external saphenous vein graft support. Multimed Man Cardiothorac Surg 2015.

19. Hess CN, Lopes RD, Gibson CM, Hager R, Wojdyla DM, et al. (2014) Saphenous vein graft failure after coronary artery bypass surgery: insights from PREVENT IV. Circulation 130: 1445-1451.

20. Milroy CM, Scott DJ, Beard JD, Horrocks M, Bradfield JW (1989) Histological appearances of the long saphenous vein. J Pathol 159: 311-316.

21. Krebs HA, Henseleit $K$ (1932) Untersuchungen über die Harnstoffbildung im Tierkörper in Hoppe-Seyler's Z Physiol Chem 210: 33-66.

22. Tonar Z, Kural T Jr, Kochová P, Nedorost L, Witter K (2012) Vasa vasorum quantification in human varicose great and small saphenous veins. Ann Anat 194: 473-481.

23. Kochová P, Witter K, Tonar Z (2014) Distribution of orientation of smooth muscle bundles does not change along human great and small varicose veins. Ann Anat 196: 67-74.

24. Samano N, Geijer H, Liden M, Fremes S, Bodin L, et al. (2015) The no-touch saphenous vein for coronary artery bypass grafting maintains a patency, after 16 years, comparable to the left internal thoracic artery: A randomized trial. The Journal of Thoracic and Cardiovascular Surgery 150: 880-888.

25. Johansson B, Samano N, Souza D, Bodin L, Filbey D, et al. (2015). The notouch vein graft for coronary artery bypass surgery preserves the left ventricular ejection fraction at 16 years postoperatively: long-term data from a longitudinal randomised trial. Open Heart 2015

26. Kopjar T, Dashwood MR (2016) Endoscopic Versus "No-Touch“ Saphenous Vein Harvesting for Coronary Artery Bypass Grafting: A Trade-Off Between Wound Healing and Graft Patency. Angiology 67: 121-132.

27. Nishimura Y, Romer LH , Lemasters JJ (1998) Mitochondrial dysfunction and cytoskeletal disruption during chemical hypoxia to cultured rat hepatic sinusoidal endothelial cells: The $\mathrm{pH}$ paradox and cytoprotection by glucose, acidotic $\mathrm{pH}$, and glycine. Hepatology 27: 1039-1049.

28. Brecht M, Brecht C, De Groot H (1992) Late steady increase in cytosolic $\mathrm{Ca} 2+$ preceding hypoxic injury in hepatocytes. Biochem J 283: 399-402.

29. Powell SR, Wapnir RA (1994) Adventitious redox-active metals in Krebs-Henseleit buffer can contribute to Langendorff heart experimental results. J Mol Cell Cardiol 26: 769-778.

30. Belzer FO, Southard JH (1988) Principles of solid-organ preservation by cold storage. Transplantation 45: 673-676.

31. Tambyraja AL, Mitchell R, Driscoll PJ, Deans C, Parks RW, et al. (2007) Glutathione supplementation to University of Wisconsin solution causes endothelial dysfunction. Transpl Immunol 18: 146-150.

32. Kerkweg U, Li T, de Groot H, Rauen U (2002) Cold-induced apoptosis of rat liver cells in University of Wisconsin solution: the central role of chelatable iron. Hepatology 35: 560-567.

33. Rauen U, Wu K, Witzke O, de Groot H (2008) Custodiol-N - a new, mechanism-based organ preservation solution. Cryobiology 57: 331 .

34. Koch A, Loganathan S, Radovits T, Sack FU, Karck M, et al. (2010) Deferoxamine, the newly developed iron chelator LK-614 and N-alpha-acetyl-histidine in myocardial protection. Interact Cardiovasc Thorac Surg 10: 181-184.

35. Zatschler B, Dieterich P, Müller B, Kasper M, Rauen U, et al. (2009) Improved vessel preservation after 4 days of cold storage: experimental study in rat arteries. J Vasc Surg 50: 397-406.

36. Wu K, Türk TR, Rauen U, Su S, Feldkamp T, et al. (2011) Prolonged cold storage using a new histidine-tryptophan-ketoglutarate-based preservation solution in isogeneic cardiac mouse grafts. Eur Heart J 32: 509-516. 